\title{
Study of bactericidal properties of carbohydrate-stabilized platinum oxide nanoparticles
}

\author{
Saeed Rezaei-Zarchi ${ }^{1}$, Saber Imani ${ }^{2 *}$, Ali mohammad Zand ${ }^{2}$, Mojtaba Saadati ${ }^{3,4}$ and Zahra Zaghari ${ }^{5}$
}

\begin{abstract}
Platinum oxide nanoparticles were prepared by a simple hydrothermal route and chemical reduction using carbohydrates (fructose and sucrose) as the reducing and stabilizing agents. In comparison with other metals, platinum oxide has less environmental pollution. Therefore, Pt is considered an appropriate candidate to deal with environmental pathogens. The crystallite size of these nanoparticles was evaluated from X-ray diffraction, atomic force microscopy, and transmission electron microscopy (TEM) and was found to be $10 \mathrm{~nm}$, which is the demonstration of EM bright field and transmission electron microscopy. The effect of carbohydrates on the morphology of the nanoparticles was studied using TEM. The nanoparticles were administered to the Pseudomonas stutzeri and Lactobacillus cultures, and the incubation was done at $37^{\circ} \mathrm{C}$ for $24 \mathrm{~h}$. The nanocomposites exhibited interesting inhibitory as well as bactericidal activity against $P$. stutzeri and Lactobacillus species. Incorporation of nanoparticles also increased the thermal stability of the carbohydrates. The results of this paper showed that carbohydrates can serve as a carrier for platinum oxide nanoparticles, and nanocomposites can have potential biological applications.
\end{abstract}

Keywords: Platinum oxide, P. stutzeri, Lactobacillus, Bactericidal effect

\section{Background}

Metal nanoparticles have different properties from those of bulk metal because of their small sizes, and thus, these materials can be employed in various photoelectronic, catalytic, magnetic, sensor, and biomedical applications [1-3]. In particular, Pt is known to inactivate microbes by interacting with their enzymes, proteins, or DNA to restrain cell proliferation or cell division [4]. Among all, capping ligands play a vital role in transforming the spherical or triangular-shaped nanoparticles to nanodevices or nanosensors of any desired shape [5]. Much of the recent research efforts have focused on developing new strategies to fabricate nanoconstructs with carbohydrates [6,7] as capping ligands because of their potential applications in the design and development of nanoscale devices and nanosensors for

\footnotetext{
* Correspondence: imani.saber@yahoo.com

${ }^{2}$ Department of Chemical Injury Research Center, Medical Science Institute, Sheikh Bahaei Street, Baqiyatallah Medical Science University, Tehran 14359-44711, Iran

Full list of author information is available at the end of the article
}

biomedical applications [8]. Carbohydrates contain many hydroxyl and carbonyl groups; these groups offer sugar-coated nanoparticle, a unique $\mathrm{H}$-bonding capabilities in constructing supramolecular architecture. Upon surface coating with nanoparticles, they provide attractive nanoconstruction abilities for building smart nanomaterials. For example, nanowires of platinum or tellurium have been constructed from glucose-stabilized platinum nanoparticles or starch-stabilized tellurium nanoparticles [9-12]. Current strategies for carbohydrate functionalization of Pt nanoparticles utilize thiol-tailored sugars as synthons [12-15]. Quinti and coworkers have developed a 'green' method to synthesize and stabilize carbohydrate-Pt nanocomposites in starch matrix using glucose as the reducing agent [16].

In this work, we developed an easy method to produce platinum oxide composites with homogeneous size distribution and then these materials were stabilized with sucrose. These stabilized nanoparticles were then used as the antimicrobial agents against Pseudomonas stutzeri and Lactobacillus cultures in further experiments.

\section{实 Springer}




\section{Methods}

The sucrose was supplied by Fibrocel - Produtos Biotecnológicos Ltda. (Ibiporã, Brazil). Platinum oxide and other reagents were commercially purchased from Sigma-Aldrich Corporation (St. Louis, MO, USA) and used as received. Aqueous solutions and bacterial suspensions were prepared using distilled deionized sterile water. Agar, tryptone, and yeast extract of Bacto ${ }^{\mathrm{TM}}$, used for the microbiological culture media, were purchased from Himedia (Mumbai, India). The P. stutzeri and Lactobacillus strains were taken from the Central Laboratory of Pathology, Yazd. All reagents were of analytical grade and used without further purification.

\section{Syntheses of carbohydrate-stabilized platinum oxide nanoparticles}

In a typical experiment, $1.7 \mathrm{~g}\left(1.0 \times 10^{-2} \mathrm{~mol}\right)$ of platinum oxide (Sigma-Aldrich, 99.9+ \%) was dissolved in $100 \mathrm{~mL}$ of deionized water. Then, the solution platinum oxide was precipitated with $0.62 \mathrm{~g}\left(1.55 \times 10^{-2} \mathrm{~mol}\right)$ of sodium hydroxide (Sigma-Aldrich, 99+ \%). An obtained precipitate of platinum oxide was filtered and dissolved in $100 \mathrm{~mL}$ of aqueous ammonia $(0.4 \% \mathrm{w} / \mathrm{w}$, $2.3 \times 10^{-2} \mathrm{~mol}$ ) until a transparent solution of platinumammonium complex was formed. Next, $2.5 \mathrm{~g}$ $\left(8.9 \times 10^{-3} \mathrm{~mol}\right)$ of oleic acid (Sigma-Aldrich, $\left.99+\%\right)$ was added dropwise into the obtained complex, and the resulting solution was gently stirred for $2 \mathrm{~h}$ at room temperature until the complete homogeneity of the reaction mixture was achieved. Finally, $2 \mathrm{~g}\left(1.11 \times 10^{-2} \mathrm{~mol}\right)$ of glucose was added to the mixture at room temperature with gentle stirring. The reduction process of silver complex solution (in quartz glass) was initiated with UV-irradiation (UV MILTON ROY Company, Ivyland, PA, USA; Spectrum 21). UV treatment was carried out for $8 \mathrm{~h}$ under vigorous stirring without additional heating. An UV lamp ( $k=365 \mathrm{~nm}, 35 \mathrm{~W})$ was used as light source to stimulate the reduction process. After $8 \mathrm{~h}$ of irradiation, the transparent dispersion obtained oleic acid-stabilized platinum oxide nanoparticles (platinum oxide concentration $=10 \mathrm{mg} \mathrm{mL}^{-1}$ ). The synthesis of platinum oxide NPs was also successfully conducted with the final $\mathrm{Pt}$ concentrations in the range of $0.1 \%$ to $2 \%$.

The TEM (H987 - Philips, Amsterdam, The Netherlands) images of the Pt oxide nanoparticles were taken by the following method: at first, a solution of Pt oxide was prepared and diluted 100 times with 50\% ethanol. A drop of this diluted solution was added to fomvar/carbon-coated grids (400 meshes) and, after drying, viewed under the TEM (Brazilian Synchroton Light Laboratory, Sao Paulo, Brazil), operating at $80 \mathrm{kV}$.

XRD (U234 - Philips) patterns were obtained in a Siemens Kristalloflex diffractometer (Siemens, Knoxville,
TN, USA) using nickel filtered $\mathrm{CuK} \alpha$ radiation from $4^{\circ}$ to $70^{\circ}$ ( $2 \theta$ angle) as shown in Figure 1. TG (STA 409 Netzsch (Selb, Germany)) was conducted using dried samples in SDT 2960 device from TA Instruments (New Castle, DE, USA). Samples were heated in open alumina pans from $40^{\circ} \mathrm{C}$ to $600^{\circ} \mathrm{C}$, under an oxidant atmosphere $\left(\mathrm{O}_{2}\right)$, using flux of $50 \mathrm{~mL} / \mathrm{min}$, at a heating rate of $10^{\circ} \mathrm{C} / \mathrm{min}$. The Pt oxide content of the $\mathrm{BC} / \mathrm{Pt}$ composites was estimated from the residue at $600^{\circ} \mathrm{C}$.

\section{Antibacterial properties of carbohydrate-stabilized platinum oxide nanoparticles}

The antimicrobial activity of sucrose-modified Pt oxide nanoparticles was investigated against $P$. stutzeri and Lactobacillus. The following solution and media were prepared to study the antimicrobial activity: (a) $\mathrm{NaCl}$ aqueous solution $(2.7 \mathrm{~g}$ of $\mathrm{NaCl}$ dissolved in $300 \mathrm{~mL}$ of distilled water), sterilized by autoclaving at $120^{\circ} \mathrm{C}$ for 20 min; (b) culture medium (Luria-Bertani (LB)) containing $1.0-\mathrm{g} \mathrm{NaCl}, 1.0$-g tryptone, 0.5 -g yeast extract of Bacto $^{\mathrm{TM}}$, and $100-\mathrm{mL}$ distilled water, sterilized by autoclaving at $120^{\circ} \mathrm{C}$ for $20 \mathrm{~min}$; and (c) solid LB medium, used to prepare petri dishes containing 3-g NaCl, 3-g tryptone, $1.5-\mathrm{g}$ yeast extract of Bacto ${ }^{\mathrm{TM}}$, $4.5-\mathrm{g}$ agar, and 300-mL distilled water. The solid LB medium was sterilized by autoclaving at $120^{\circ} \mathrm{C}$ for $20 \mathrm{~min}$.

An aliquot $(100 \mu \mathrm{L})$ of the bacterial suspension prepared previously was transferred to a test tube with $9.9 \mathrm{~mL}$ of lysogenic broth medium (LB) and homogenized. This tube contained a concentration of $10^{7}$ cells $\mathrm{mL}^{-1}$. This bacterial suspension was diluted in a saline solution to obtain a suspension containing about $10^{5}$ cells $\mathrm{mL}^{-1}$. Aliquots of $1,000 \mu \mathrm{L}$ of the suspension containing about $10^{5}$ cells $\mathrm{mL}^{-1}$ were transferred to sterile test tubes containing the samples. The test tubes were incubated in a stirring incubator at $37^{\circ} \mathrm{C}$ and stirred at $120 \mathrm{rpm}$ for $24 \mathrm{~h}$. After incubation, the content of the tubes was transferred to four Erlenmeyer flasks filled with $50 \mathrm{~mL}$ of sterile $\mathrm{NaCl}$ aqueous solution at $0.9 \%$.

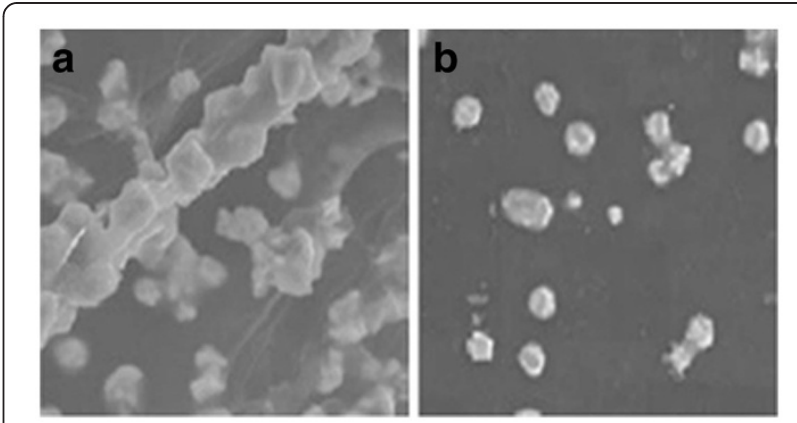

Figure 1 TEM images. (a) TEM bright field image of Pt nanoparticles. (b) TEM image of Pt nanoparticles obtained using sucrose as a reducing agent. 
An aliquot $(100 \mu \mathrm{L})$ of the content of each Erlenmeyer flask was transferred to a microtube filled with $900 \mu \mathrm{L}$ of sterile $\mathrm{NaCl}$ aqueous solution. The microtubes were then vortexes. This dilution sequence was repeated four times to obtain four dilutions. Aliquots $(100 \mu \mathrm{L})$ of these dilutions were then spread on a nutrient agar plate and incubated at $37^{\circ} \mathrm{C}$ for $24 \mathrm{~h}$; after which, the colonyforming units were counted, and the average was taken from the three plates corresponding to a particular sample. The antibacterial activity of the carbohydrate-Pt nanocomposites impregnated in bacterial cellulose was determined at different concentrations $\left(10^{3}, 10^{4}, 10^{5}\right.$, $10^{6}$, and $10^{7}$ cells $\mathrm{mL}^{-1}$ ). The experiments were carried out in triplicate. Statistical analysis was performed using Student's $t$-test, and the percentage reduction in bacterial count was calculated by the following equation:

$$
\begin{aligned}
& \text { Percentage reduction in bacterial count }(\%) \\
& =\left[\frac{\text { viable CFU in an hour }- \text { viable CFU in } 24 \mathrm{~h}}{\text { viable CFU in an hour }}\right] \\
& \times 100
\end{aligned}
$$

\section{Results and discussion}

Pt oxide nanoparticles could be successfully synthesized in the sucrose matrix. The reduction was fastest in the case of sucrose followed by waxy corn and soluble starch while stability of nanoparticles followed the order soluble starch $>$ waxy corn starch $>$ sucrose (data not shown). Thus, the size and molecular weight were important for stabilization of the nanoparticles.

Figure 1a shows the TEM image of Pt oxide nanoparticles alone. Figure 1b shows the TEM image of Pt oxide modified with sucrose. The sucrose reduction occurred only after heating at $80^{\circ} \mathrm{C}$ for $4 \mathrm{~h}$. This is required because the more hydrolyzed the carbohydrate the better its ability to act as a reducing agent. UV-visible illumination was used to enhance the reduction capacity of sucrose where it is hydrolyzed, and the hydrolyzed products then reduce the metal. The time taken for reduction is also very short (30 s).

UV-vis absorption spectrum of carbohydratestabilized Pt oxide nanoparticles in aqueous solution was recorded after sufficient dilution as demonstrated in Figure 2. The characteristic absorption peak due to the surface-plasmon resonance of Pt colloids was observed within the range of 415 to $425 \mathrm{~nm}$.

Although the exact mechanism of the formation of the nanostructures is difficult to know, we think that the simple structure of sucrose could serve as a directing template for the growth of $\mathrm{Pt}$ nanoparticles. Figure 3 demonstrates the simulated XRD patterns of sucrosestabilized Pt oxide nanoparticles. All Bragg's reflections representing b111N, b200N, b220N, and b311N planes

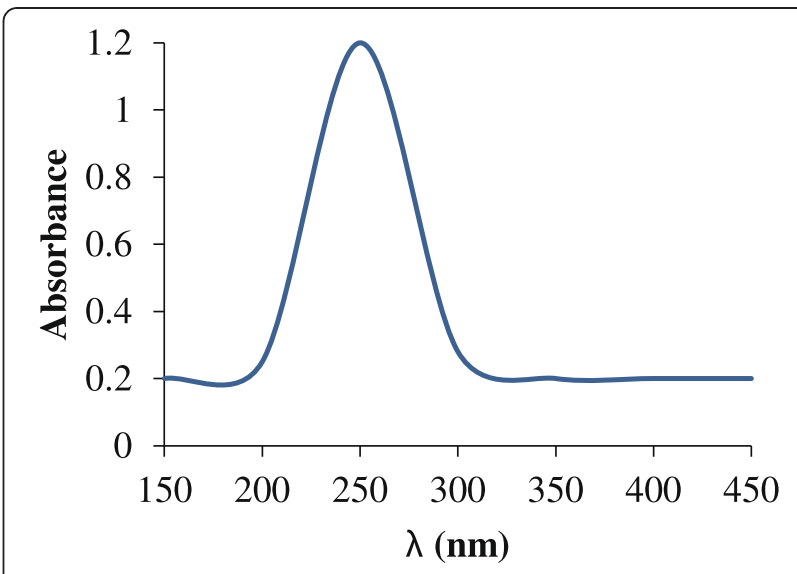

Figure 2 UV-visible spectrum of Pt oxide nanoparticles modified with sucrose.

of FCC crystal structures due to metallic Pt are observed. About 7\% of $\mathrm{Pt}$ is present in nanocomposites, and oxygen comes from the surrounding organic matter.

Figure 4 shows the atomic force microscopic image of the sucrose-stabilized $\mathrm{Pt}$ oxide nanoparticles. The carbohydrate-stabilized aqueous solution of $\mathrm{Pt}$ oxide nanoparticles exhibited antibacterial activity against $P$. stutzeri and Lactobacillus bacteria even at concentrations as low as $0.049 \mathrm{mg} / \mathrm{L}$. The photographs in Figures 5 and 6 clearly show the zone of inhibition for carbohydrate-Pt nanocomposites against $P$. stutzeri and Lactobacillus, respectively. Similar results were obtained against Staphylococcus aureus (data not shown).

The digital photographs in Figure 5a,b represents MIC and $\mathrm{MBC}$ tests in $\mathrm{Pt}$ oxide-sucrose nanocomposite against $P$. stutzeri, respectively. This figure specifies that $\mathrm{MIC} / \mathrm{MBC}$ rate is about $0 / 5$.

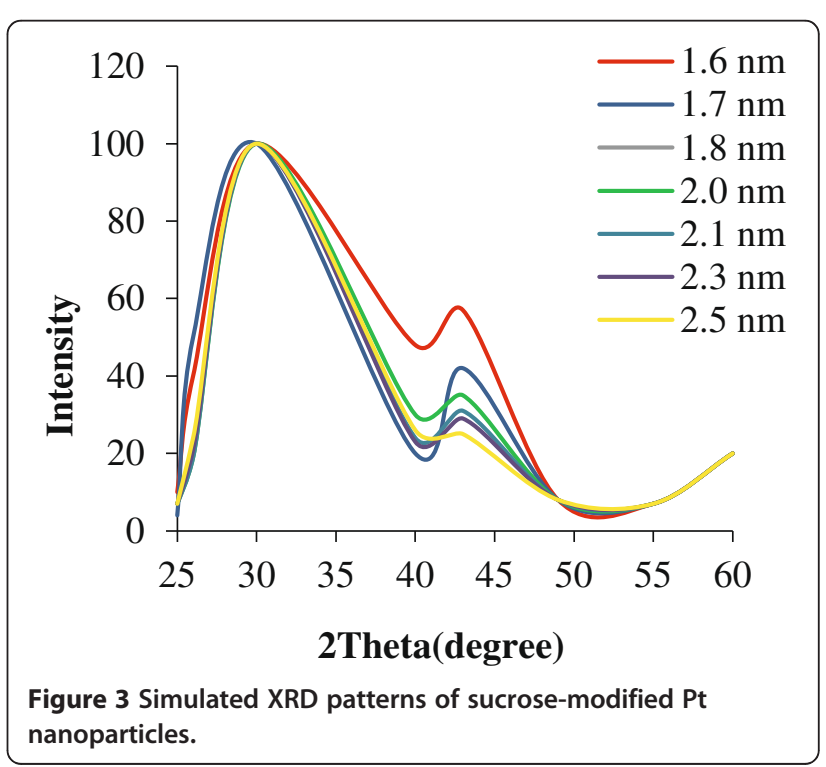




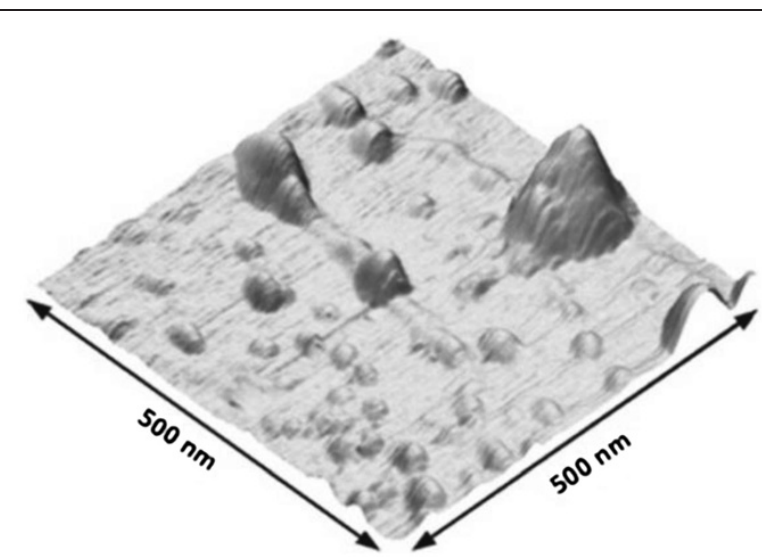

Figure 4 AFM image of the platinum oxide nanoparticles.

On the other hand, Figure 6a,b shows the same parameters against Lactobacillus strain. The effectiveness of sucrose nanocomposites was proven to be highly effective. Therefore, it could be concluded that Pt oxide nanoparticles could be released through aqueous carbohydrate solutions owing to the stable dispersion at molecular level and the slow diffusion from the stabilizing medium.

Platinum oxide nanoparticles were obtained by a green approach using sucrose as a reducing as well as stabilizing agent [17-19]. The nanoparticles exhibited interesting morphology when synthesized under hydrothermal conditions in the matrix of sucrose-rich medium. These nanocomposites exhibited high thermal stability as well as bactericidal effect against $P$. stutzeri and Lactobacillus. Thus, carbohydrates can serve as a carrier for platinum oxide nanoparticles, and nanocomposites can have potential biological applications [20-22].

\section{Conclusion}

The present study reveals the characteristics of antibacterial effect of carbohydrate-stabilized platinum oxide nanoparticles. Given the fact that the nanocomposition of platinum oxide can be used in biomedicine product,
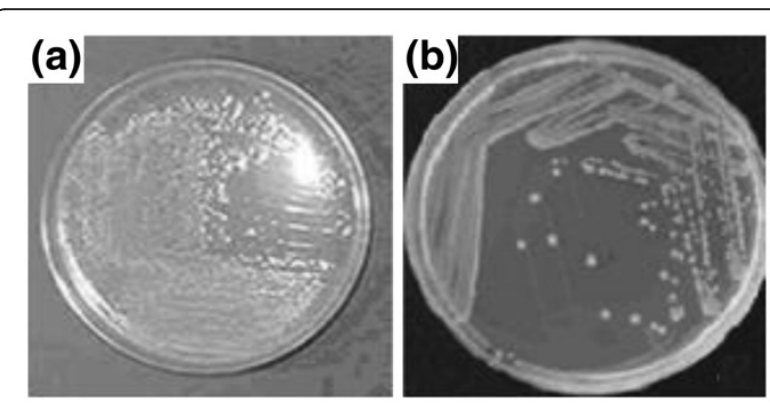

Figure 5 Digital photographs. Representing (a) MIC and (b) MBC tests against $P$. stutzeri in Pt-sucrose nanocomposite incubated at $37^{\circ} \mathrm{C}$ for $24 \mathrm{~h}$

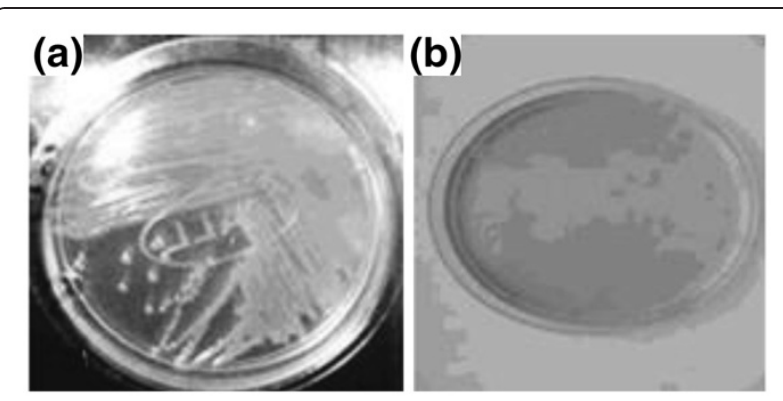

Figure 6 Digital photographs. Representing (a) MIC and (b) MBC tests against Lactobacillus in Pt-sucrose nanocomposite incubated at $37^{\circ} \mathrm{C}$ for $24 \mathrm{~h}$.

nanofilters consequently contained more antibacterial active sites than other antibacterial agents.

\section{Competing interests}

The authors declare that they have no competing interests.

\section{Authors' contributions}

SRZ and ZZ designed and synthesized the carbohydrate-stabilized platinum oxide nanoparticles, guided the contact angle analysis, and prepared the manuscript. AMZ and SI facilitated and made the antibacterial and biological samples, guided the contact angle analysis, and prepared the manuscript. MS participated in the SEM analysis and prepared the manuscript. All authors read and approved the final manuscript.

\section{Acknowledgments}

The authors greatly appreciate the financial support from Payame Noor University, Yazd and Imam Houssein University for running the present project.

\section{Author details}

'Department of Biology, Basic Science Institute, University Street,

Payam-e-Noor University, Yazd 89418-57417, Iran. ${ }^{2}$ Department of Chemical Injury Research Center, Medical Science Institute, Sheikh Bahaei Street,

Baqiyatallah Medical Science University, Tehran 14359-44711, Iran.

${ }^{3}$ Department of Biology, Basic Science Institute, Shahid Babaei Street, Imam Houssein University, Tehran 479231-98662, Iran. ${ }^{4}$ Department of Applied Biotechnology and Environmental Research Center, Sheikh Bahaei Street, Baqiyatallah Medical Science University, Tehran 14359-44711, Iran.

${ }^{5}$ Department of Biology, Basic Science Institute, Nakhl Street, Payam-e-Noor University, Tehran 19395-4697, Iran.

Received: 3 April 2011 Accepted: 28 February 2012

Published: 24 September 2012

\section{References}

1. Shevchenko, EV, Talapin, DV, Kotov, NA, O'Brien, S, Murray, CB: Structural diversity in binary nanoparticle superlattices. Nature 439, 55-59 (2006)

2. Wang, $X$, Zhuang, J, Peng, Q, Li, YD: A general strategy for nanocrystal synthesis. Nature 437, 121-124 (2005)

3. Portney, NG, Singh, K, Chaudhary, S, Destito, G, Schneemann, A, Manchester, M, Ozkan, M: Organic and inorganic nanoparticle hybrids. Langmuir 21, 2098-2103 (2005)

4. Maye, MM, Lim, IIS, Luo, J, Rab, Z, Rabinovich, D, Liu, TB, Zhong, CJ: Mediator-template assembly of nanoparticles. J. Am. Chem. Soc. 127, 1519-1529 (2005)

5. Chane-Ching, JY, Cobo, F, Aubert, D, Harvey, HG, Airiau, M, Corma, A: A general method for the synthesis of nanostructured large-surface-area materials through the self-assembly of functionalized nanoparticles. Chem. Eur. J. 11, 979-987 (2005)

6. Kim, BS, Hong, DJ, Bae, J, Lee, M: Controlled self-assembly of carbohydrate conjugate rod-coil amphiphiles for supramolecular multivalent ligands. J. Am. Chem. Soc. 127, 16333-16337 (2005) 
7. Barrientos, AG, de la Fuente, JM, Rojas, TC, Fernandez, A, Penades, S: Gold glyconanoparticles: synthetic polyvalent ligands mimicking glycocalyx-like surfaces as tools for glycobiological studies. Chem. Eur. J. 9, 1909-1921 (2003)

8. Rojas, TC, de la Fuente, JM, Barrientos, AG, Penades, S, Ponsonnet, L, Fernandez, A: Gold glyconanoparticles as building blocks for nanomaterials design. Adv. Mater. 14, 585-588 (2002)

9. Zand, AM, H Khani, P, Imani, S, Rezaei, M, Rezaei-Zarchi, S: Determining the antibacterial effect of $\mathrm{ZnO}$ nanoparticle against the pathogenic bacterium, Shigella dysenteriae (type 1). International Journal of Nano Dimension (IJND) 1(4), 279-285 (2010)

10. Reynolds, AJ, Haines, AH, Russell, DA: Gold glyconanoparticles for mimics and measurement of metal ion mediated carbohydrate-carbohydrate interactions. Langmuir 22, 1156-1163 (2006)

11. Halkes, KM, de Carvalho, SA, Elizabeth, C, Maliaars, P, Gerwig, GJ, Kamerling, JP: Facile method for the preparation of gold glyconanoparticles from free oligosaccharides and their applicability in carbohydrate-protein interaction studies. Eur. J. Org. Chem. 12, 3650-3659 (2005)

12. De la Fuente, JM, Eaton, P, Barrientos, AG, Menendez, M, Penades, S: Thermodynamic evidence for $\mathrm{Ca} 2+-$ mediated self-aggregation of Lewis $X$ gold glyconanoparticles. A model for cell adhesion via carbohydratecarbohydrate interaction. J. Am. Chem. Soc. 127, 6192-6197 (2005)

13. de la Fuente, JM, Barrientos, AG, Rojas, TC, Rojo, J, Canada, J, Fernandez, A, Penades, S: Gold glyconanoparticles as water-soluble polyvalent models to study carbohydrate interactions. Angew. Chem. Int. Ed. 40, 2258-2261 (2001)

14. Ipe, BI, Yoosaf, K, Thomas, KG: Functionalized gold nanoparticles as phosphorescent nanomaterials and sensors. J. Am. Chem. Soc. 128, 1907-1913 (2006)

15. Perez, JM, Josephson, L, Weissleder, R: Use of magnetic nanoparticles as nanosensors to probe for molecular interactions. Chem. Bio. Chem. 5, 261-264 (2004)

16. Quinti, L, Weissleder, R, Tung, CH: A fluorescent nanosensor for apoptotic cells. Nano. Lett. 6, 488-490 (2006)

17. Imani, S, Zagari, Z, Rezaei-Zarchi, S, Zand, AM, Dorodiyan, Bariabarghoyi, H, Lotfi, F: Antibacterial effect of $\mathrm{CrO}$ and $\mathrm{CoFe}_{2} \mathrm{O}_{4}$ nanoparticles upon Staphylococcus aureus. 3, 119-125 (2011)

18. de la Fuente, JM, Penades, S: Types, synthesis and applications in glycoscience, biomedicine and material science. Biochim. Biophys. Acta $1760,636-651$ (2006)

19. Lu, QY, Gao, F, Komarneni, S: A green chemical approach to the synthesis of tellurium nanowires. Langmuir 21, 6002-6005 (2005)

20. Liu, JC, Qin, G, Ravindran, P, Ikushima, Y: Facile "green" synthesis, characterization, and catalytic function of $\beta$-d-glucose-stabilized $\mathrm{Au}$ nanocrystals. Chem. Eur. J. 12, 2131 (2006)

21. Raghuraman, K, Katti, KK, Barbour, LJ, Pillarsetty, N, Barnes, CL, Katti, KV: Characterization of supramolecular $\left(\mathrm{H}_{2} \mathrm{O}\right) 18$ water morphology and water-methanol $\left(\mathrm{H}_{2} \mathrm{O}\right) 15\left(\mathrm{CH}_{3} \mathrm{OH}\right)_{3}$ clusters in a novel phosphorus functionalized trimeric amino acid host. J. Am. Chem. Soc. 125, 6955-6961 (2003)

22. Raghuraman, K, Pillarsetty, N, Volkert, WA, Barnes, C, Jurisson, S, Katti, KV: Exceptional kinetic propensity of hydroxymethyl phosphanes toward Rh(III) stabilization in water. J. Am. Chem. Soc. 124, 7276-7277 (2002)

doi:10.1186/2228-5326-2-21

Cite this article as: Rezaei-Zarchi et al.: Study of bactericidal properties of carbohydrate-stabilized platinum oxide nanoparticles. International Nano Letters 2012 2:21.

\section{Submit your manuscript to a SpringerOpen ${ }^{\circ}$ journal and benefit from:}

- Convenient online submission

- Rigorous peer review

- Immediate publication on acceptance

- Open access: articles freely available online

- High visibility within the field

- Retaining the copyright to your article

Submit your next manuscript at $\gg$ springeropen.com 